\title{
Biphasic Pulmonary Blastoma Associated with Cerebral Metastasis
}

\author{
Dalokay KILIC ${ }^{1}$, Cem YILMAZ³ , Merih TEPEOGLU², Cigdem VURAL ${ }^{2}$, Hakan CANER ${ }^{3}$ \\ 'Baskent University, School of Medicine, Departments of Thoracic Surgery, Ankara, Turkey \\ 'Baskent University, School of Medicine, Departments of Pathology, Ankara, Turkey \\ ${ }^{3}$ Baskent University, School of Medicine, Departments of Neurosurgery, Ankara, Turkey
}

\section{ABSTRACT}

Pulmonary blastoma is a very rare malignant tumor of the lungs. A biphasic pulmonary blastoma was histologically diagnosed by a characteristic finding as it was mainly constituted of immature tumor tissue that had both epithelial and mesenchymal components. We present a case of a 68-year-old man with biphasic pulmonary blastoma. The patient underwent cranial metastatectomy and left lung upper lobectomy. Although the tumor was resected, there was rapid metastasis to the cranial, liver, kidney and multiple bones. Although radiotherapy and chemotherapy were administrated, the patient died about 6 months postoperatively. Close follow-up and aggressive chemotherapy should be considered for such tumours. In the light of this case, the authors review the pathologic, clinical, radiological and therapeutic features of this very rare malignant lung tumor.

KEYWORDS: Biphasic pulmonary blastoma, Cerebral metastasis, Treatment, Surgery

\section{INTRODUCTION}

Biphasic Pulmonary Blastoma (BPB) is a very rare malignant lung tumor with an immature mesenchymal and epithelial component resembling fetal lung (1). In order to define potential therapeutic targets in pulmonary blastoma. most of the authors have been reported to have a poor prognosis despite treatment $(1,5)$.

We report a case of pulmonary blastoma that presented to and was treated at our unit and review their clinical, radiological, and pathological variability.

\section{CASE REPORT}

A 68-year-old male presented with a pulmonary blastoma associated with a solitary cerebral metastasis. His medical history revealed a smoking history of 15 pack-years. The patient was admitted to our hospital with the chief complaints of head pain and chest pain on the left side. Computed tomography of the chest revealed a well-demarcated and heterogeneously enhanced tumor ( $11 \mathrm{~cm}$ in diameter) in the upper lobe of the left lung (Figure 1A). Cranial magnetic resonance imaging showed a mass on the frontal lobe (Figure 1B). Although a histological diagnosis could not be obtained by transthoracic biopsy, image analyses led us to suspect it to be malignant. Firstly, the patient underwent cranial mass resection and then left upper lobectomy (Figure 2) and mediastinal lymph node dissection. Histological examination of the cranial lesion revealed a tumor that was composed of immature mesenchymal and epithelial elements (Figure 3A). Immunohistochemically, the epithelial component of the tumor was positive with epithelial membrane antigen (EMA) (Figure 3B), TTF-1 and focally CD-56. P63 and Cytokeratin 5/6 were negative. Based on these morphological and immunohistochemical features, the lesion was reported as metastatic biphasic pulmonary blastoma. After two weeks, lobectomy was performed and macroscopically, a necrotic mass, which was $10.5 \times 9 \times 5 \mathrm{~cm}$ in size, was noted. Histologically, a biphasic tumor with a mixture of primitive epithelial and mesenchymal components was seen (Figure 4). The epithelial component of the tumor was composed of well- 
Kilic D. et al: Cerebral Metastasis of Biphasic Pulmonary Blastoma

differentiated tubular glands that were lined by tall, columnar cells. The mesencyhmal component contained immature sarcomatous tumor tissue composed of small, oval to spindle cells. Immunohistochemically, EMA, AE1/AE3 and TTF-1 were positive in the epithelial component, while vimentin was positive in the mesenchymal tumoral areas.
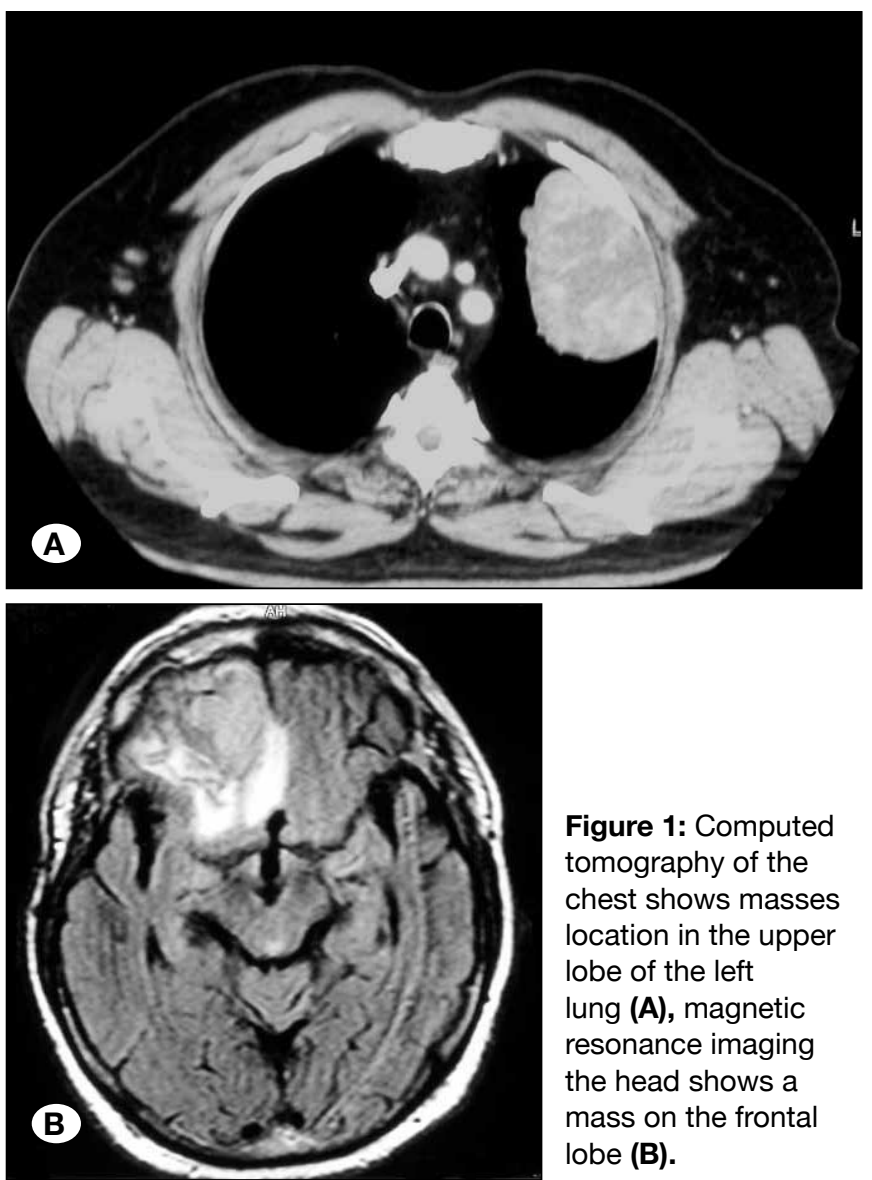

Figure 1: Computed tomography of the chest shows masses location in the upper lobe of the left lung (A), magnetic resonance imaging the head shows a mass on the frontal lobe (B).

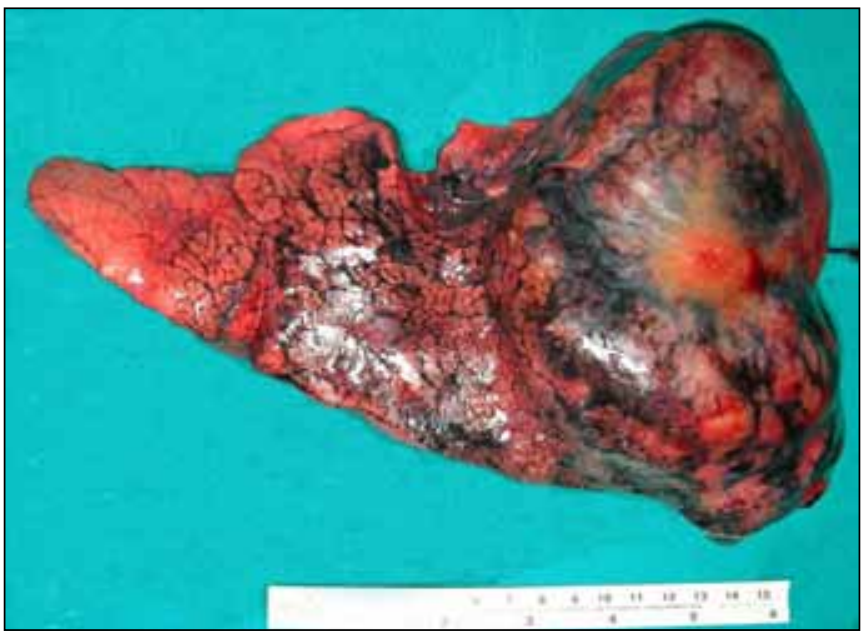

Figure 2: Surgical specimen shows the mass in the left lung superior lobe.
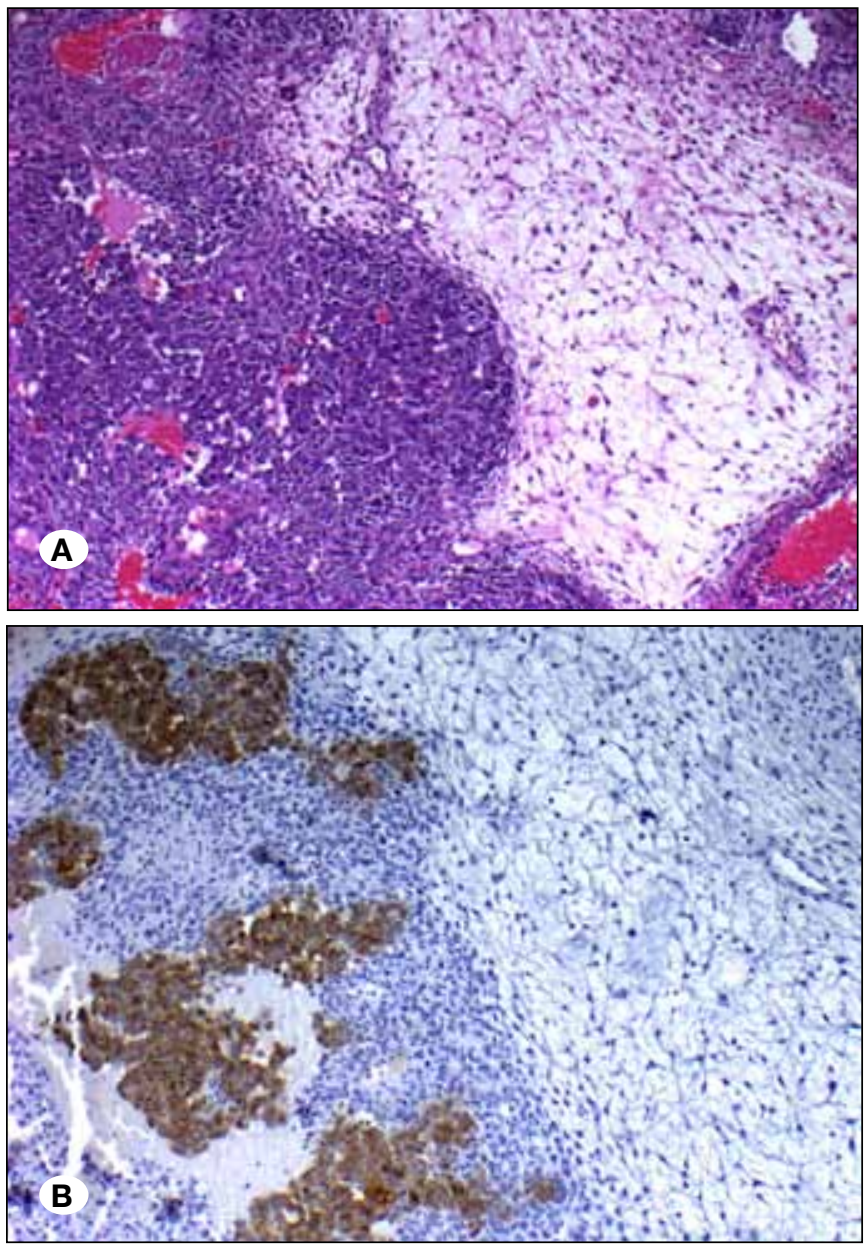

Figure 3: Histopathology of cranial lesion. Tumor consists of a spindle cell and malignant glandular component (Hematoxylineosin $\times 100)(A)$. The epithelial component is positive with EMA immunohistochemistry (EMA x100) (B).

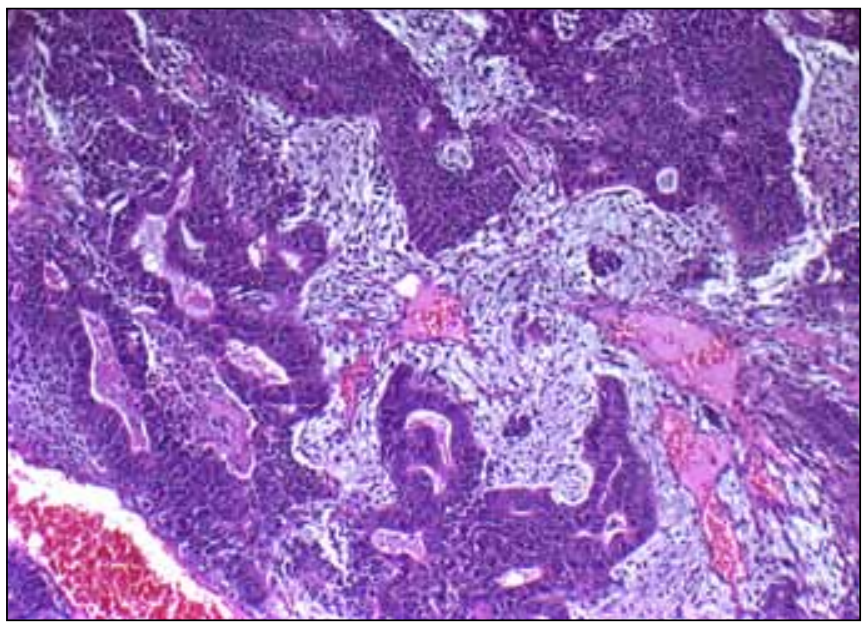

Figure 4: Histopathology of the lesion in the lung, showing pulmonary blastoma with a characteristic biphasic picture includes both immature carcinomatous tumor tissue as well-differentiated tubular glands and immature mesenchymal sarcomatous tumor tissue composed of small oval to spindle cells (Hematoxylin-Eosin $\mathrm{x} 100)$. 
Cranial recurrence was observed and re-resection was performed two months after surgery, and radiation and chemotherapy were administered. Although he recovered well postoperatively, he died 6 months after surgery with multiple metastases to the bone and liver.

\section{DISCUSSION}

Pulmonary blastoma is an uncommon primary lung malignancy with a frequency of only $0.3-0.5 \%$ of all primary lung tumors $(11,13)$. Over 200 cases have been reported so far worldwide since the first description of the tumor by Barrett in 1945 (3).

Pulmonary blastomas were designated 'embryomas' by Barnard in 1952 (2) and in 1961 Spencer recategorised this neoplasm as a pulmonary blastoma (20). Many authors have reported monophasic pulmonary blastoma as the epithelial form, which is now called well-differentiated fetal adenocarcinoma, and the other form with only mesenchymal components was defined by Manivel et al. $(5,10,15)$. Only the mesenchymal form called pleuropulmonary blastoma is observed in childhood (18). Pulmonary blastoma can therefore be classified into three groups: biphasic pulmonary blastoma (BPB), well-differentiated fetal adenocarcinoma (WDFA) and pleuropulmonary blastoma (PPB). However, according to the 1999 classification of the World health Organization, WDFA and PPB are categorized as a variant of adenocarcinoma and soft tissue sarcoma of the lung (21).

Biphasic pulmonary blastoma is a subtype of these tumors, composed of immature epithelial and mesenchymal tissues, which may recapitulate early embryological lung development. Under the microscope, the globular component resembles immature bronchus and connective tissue as seen in the embryonic lung. BPB is more frequent in older people and in males and tends to affect adult ages. The etiology is still uncertain but there is strong evidence in the literature showing the correlation between cigarette smoking and PB (23). The types of p53 mutations are also similar to the p53 mutations found in other lung cancers (4). Our patient had a history of smoking.

Immunohistochemical studies are useful in diagnosis BPB. Especially with a combination of both epithelial markers such as epithelial membrane antigen (EMA), Cytokeratin marker (CAM 5.2, CK 5/6), AE1/AE3, and a mesenchymal marker such as Vimentin, each component can be clearly highlighted from each other. CD-34 and S-100 protein stain both epithelial and mesenchymal components (16). Also, Hansen et al reported novel marker as KIT (CD117) expression of BPB (6). In our patient, EMA, AE1/AE3 and TTF-1 were positive in the epithelial component, and vimentin was positive in the mesenchymal areas. Similarly with Hansen, we found CD117 positivity in our tumor. CD56, P63, CK5/6, CD 34 and S100 were negative.

Symptomatology varies from asymptomatic to symptoms of a non-specific pulmonary disease. Cough, hemoptysis, dyspnea, chest pain, respiratory distress, fever, anorexia and weight loss are the most common presenting features (1). In our patient, the head pain and chest pain were the major symptoms.
Considerable immunoreactivity for alpha-fetoprotein (AFP) was reported in the literature (7). It was pointed out that the epithelial cells of PB might occasionally de-differentiate into cells functionally resembling fetal hepatic, foregut and yolk sac cells expressing AFP. Unfortunately AFP levels were not measured in our patient.

The most common roentgenologic pattern is a well-demarcated peripheral lesion, encapsulated by compression or atelectatic lung tissue; although in some cases there is a tendency to lobulation and cavitation. Generally, the tumor has massive necrosis. The size of the mass varies from a small peripheral nodule to a mass occupying the entire lobe or hemithorax (12, 22). In our patient, the well-demarcated mass was shown on the cranial and chest images.

The treatment of choice has been surgical excision, radiation and, in selected cases, a combination of chemotherapy with radiation (19). Adjunctive therapy is still controversial because of lack of data. The prognosis of this malignancy is poor; overall five-year survival is approximately 16 percent (8). Koss et al mentioned that the median survival was approximately one year (9). No correlation has been established between histopathologic criteria and survival. The factors that indicate poor prognosis are tumor recurrence, metastasis at initial presentation, tumor size over $5 \mathrm{~cm}$ and lymph node and distant organ metastasis. Liver, central nervous system and bones are the most frequent location of distant metastases. Rapid progression has been reported despite radical resection (17). Our patient survival is 6 months due to distant multiorgan metastasis. Macher-Goeppinger $\mathrm{S}$ et al mentioned that detection of EGFR expression and mutation in PB suggests EGFR inhibition as a potential therapeutic option in the treatment of advanced PB. Moreover, the data confirm a crucial role of CTNNB1 mutations in the pathogenesis of PB, and indicate that CTNNB1 gene sequencing may be useful in distinguishing PB from other types of lung cancer (14).

Biphasic pulmonary blastomas are very rare tumors but can present with various clinical features and especially pathology diagnoses. Clinicians must be aware of the recurrence cerebral metastases despite the cranial metastatectomy. Early detection and treatment may improve prognosis. Further studies with more patients are needed to determine the characteristics of the tumor.

\section{REFERENCES}

1. Adluri RK, Boddu SR, Martin-Ucar A, Duffy JP, Beggs FD, Morgan WE: Pulmonary blastoma--a rare tumor with variable presentation. Eur J Cardiothorac Surg 29:236-239, 2006

2. Barnard WG: Embryoma of lung. Thorax 7:229-301, 1952

3. Barrett NR, Barnard WG: Some unusual thoracic tumors. $\mathrm{Br} \mathrm{J}$ Surg 32: 447-457,1945

4. Bodner SM, Koss MN: Mutations in the p53 gene in Pulmonary blastomas: Immunohistochemical and molecular studies. Hum Pathol 27: 1117-1122, 1996

5. Daniel C, Toper C, Régnard JF, Livartowski A, Ruffié P: Pulmonary blastoma in an adult. Rev Mal Respir 27:1096-1100, 2010 
6. Hansen T, Bittinger F, Kortsik C, Wagner B, Kirkpatrick CJ: Expression of KIT (CD117) in biphasic pulmonary blastoma. Novel data on histogenesis. Lung 181:193-200, 2003

7. Kasuga I, Miyamoto D, Ichinose $\mathrm{Y}$, Chimangul W, Minemura $\mathrm{K}$, Utsumi K, Yonemaru M, Serizawa H, Ebihara Y, Toyama K: Alphafetoprotein producing pulmonary blastoma in a patient with systemic sclerosis: Pathogenetic analysis. Eur Respir J 11:11851187, 1998

8. Koss NM, Hochholzer L, O'Leary T: Pulmonary blastomas. Cancer 67: 2368-2381, 1991

9. Koss M, Travis W, Moran C: Pulmonary sarcomas, blastomas, carcinosarcomas and teratomas. In: Hasleton PS (ed). Spencer's Pathology of Lung. 5th ed. New York: McGraw-Hill, 1996:10651109

10. Kradin RL, Young RH, Dickersin GR, Kirkham SE, Mark EJ: Pulmonary blastoma with argyrophil cells and lacking sarcomatous features (pulmonary endodermal tumor resembling fetal lung). Am J surg Pathol 6:165-172, 1982

11. Larsen H, Sorensen JB Pulmonary blastoma: A review with special emphasis on prognosis and treatment. Cancer Treat Rev 22:145-160, 1996

12. Lee HJ, Goo JM, Kim K, WIm JG, Kim JH: Pulmonary blastoma radiologic findings in five patients. Clin Imag 28:113-118, 2004

13. Liman ST, Altinok T, Topcu S, Tastepe Al, Uzar A, Demircan S, Demirag F: Survival of biphasic pulmonary blastoma. Respir Med 100:1174-1179, 2006

14. Macher-Goeppinger S, Penzel R, Roth W, Dienemann H, Thomas $M$, Schnabel PA, Schirmacher P, Bläker H: Expression and mutation analysis of EGFR, C-KIT, and \{beta\}-catenin in pulmonary blastoma. J Clin Pathol 64(4):349-353, 2011

15. Manivel JC, Priest JR, Watterson J, Steiner M, Woods WG, Wick MR, Dehner LP: Pleuropulmonary blastoma. The so-called pulmonary blastoma of childhood. Cancer 62:1516-1526, 1988
16. Nakatani $\mathrm{Y}$, Miyagi $\mathrm{Y}$, Takemura T, Oka T, Yokoi T, Takagi M, Yokoyama S, Kashima K, Hara K, Yamada T, Nozawa A, Inayama Y, Sakamoto K, Ogawa N, Kitamura H, Resl M, Cho SH, Koss MN, Mark EJ: Aberrant nuclear/cytoplasmic localization and gene mutation of beta-catenin in classic pulmonary blastoma: Beta-catenin immunostaining is useful for distinguishing between classic pulmonary blastoma and a blastomatoid variant of carcinosarcoma. Am J Surg Pathol 28:921-927, 2004

17. Ondo $\mathrm{K}$, Ishida $\mathrm{T}$, Yamazaki $\mathrm{K}$, Ishii $\mathrm{T}$, Yamamoto $\mathrm{K}$, Odashiro T, Saito G, Kido A, Sasaki Y, Yukaya H, Fujiwara M, Sugio K: Pulmonary blastoma in an adult. A case with rapid progression. Scand Cardiovasc J 32: 247-249, 1998

18. Priest JR, Magnuson J, Williams GM, Abromowitch M, Byrd R, Sprinz P, Finkelstein M, Moertel CL, Hill DA: Cerebral metastasis and other central nervous system. Complications of pleuropulmonary blastoma. Pediatr Blood Cancer 49: 266-273, 2007

19. Robert J, Pache JC, Seium Y, Perrot M, Spiliopoulos A: Pulmonary blastoma: report of 5 cases and identification of clinical features suggestive of the disease. Eur J Cardiothorac Surg 22:708-711, 2002

20. Spencer H: Pulmonary blastoma. J Pathol Bacteriol 82:161-165, 1961

21. Trawis WD, Colby TV, Corin B: Histological typing of lung and pleural tumors. World Health Organization, International Hystological Classification of Tumors. 3rd ed. Berlin:Springer, Verlag, 1999: 43-44

22. Walker RI, Suvarna K, Matthews S: Case report: Pulmonary blastoma: Presentation of two atypical cases and review of the literature. $\mathrm{Br} \mathrm{J}$ Radiol 78:437-440, 2005

23. Zaidi A, Zamvar V, Macbeth F, Gibbs AR, Kulatilake N, Butchart EG: Pulmonary blastoma: Medium-term results from a regional center. Ann Thorac Surg 73:1572-1575, 2002 